\title{
COMMENTARY
}

\section{Chronic Wounds: The Persistent Infection Problem}

\author{
Nicola Davis*
}

\begin{abstract}
Chronic wounds heal poorly and can have a huge impact on a sufferer's life. They are caused by a number of factors, one of which is the presence of persistent infections. Many standard treatments are unsuccessful at destroying these infections as the bacteria form a biofilm. Biofilms encase the bacteria, preventing immune cells from destroying them. There are multiple bacterial species within a biofilm, sometimes with antibiotics resistance, and which species are present changes over time. The changing, multi-species nature of biofilms can make finding an effective antibiotic treatment difficult. Also, bacteria in biofilms genetically differ from planktonic bacteria, and are often less susceptible to antibiotics. Additionally, biofilms are thought to reduce the access of antibiotics to the bacteria within. These reasons are discussed in further detail in this review, along with some of the reasons why bacteria can prevent wound closure.
\end{abstract}

Chronic wounds are injuries that heal poorly, failing to proceed through the normal healing stages, and generally taking over three months to close. Despite our advances in medicine and sanitation they remain a common global affliction. They are a significant health care cost, but equally importantly are often extremely painful and have a debilitating impact on a person's quality of life. One cause of chronic wounds is bacterial infection, which is addressed in this article.

Chronic wounds are often overlooked as a major disease, but for sufferers they can have substantial effects on everyday life. They can prevent participation in normal activities and in some cases severely impair mobility. They are unsightly, and may emit offensive odours, problems which can cause the sufferer embarrassment, and lead to

\footnotetext{
* Cell and Developmental Biology, UCL, United Kingdom nicola.crow.10@ucl.ac.uk
}

social isolation (Posnett and Franks 2008; Green and Jester 2009). Chronic wounds require regular treatment, and in extreme circumstances amputation of the affected limb may be necessary, which has a considerable psychological impact (American Diabetes Association 1999).

There are a number of groups of people at risk of chronic wounds, including but not limited to those with diabetes, the obese and the elderly (Falanga 1993). Advances in medicine have led to an increasingly ageing population and also better survival of people with chronic wound risk associated illnesses. Subsequently, chronic wounds have become a growing problem.

The causes of impaired healing in chronic wounds are wide-ranging, and differ between individuals. However impaired healing is generally attributed to four main factors: oxygen starvation to tissues; damage to tissues when oxygen supply is returned; a patient's underlying disease state, such as diabetes; and bacte- 
rial infections (Mustoe et al 2006). Here I will discuss why bacteria are a persistent problem in chronic wounds, and how they can prevent wound closure in people affected by this debilitating condition.

As chronic wounds are open for a prolonged period, they are at a greater risk of bacterial contamination, compared to acute wounds. Despite the increased risk of contamination it has only recently become accepted that the majority of chronic wounds are infected with bacteria, and that infections are one of the fundamental causes of impaired healing (Schierle et al 2009).

Infections in chronic wounds often display a marked resistance to treatments, and a high re-occurrence rate, making them difficult to treat effectively. This persistence of infection in chronic wounds is thought to be a result of the bacteria forming what is known as a biofilm (Costerton 2007; James et al 2008). Historically, bacteria have been studied in their planktonic form - as individual bacteria free-floating in fluid. It is now accepted that bacteria only take this form transiently in nature; instead they form aggregates, embedded in a self-produced matrix, called a biofilm, which can be produced in as little as twenty-four hours (Costerton 2007; Davis et al 2008; Gurjala et al 2011). The matrix provides protection to the bacteria within it from external aggressors by forming a tight network, which encases the small bacteria. Much larger human immune cells, whose role is to consume and destroy invading pathogens, are prevented from accessing the bacteria within. The inability of immune cells to reach the bacteria limits the effectiveness of a person's immune system to clear an infection once a biofilm has formed, resulting in a need for frequent treatment with antimicrobials.

However, antibiotics have limited success in killing bacteria within chronic wounds (Drenkard 2003). It has been suggested that the matrix can limit the access of antibiotics to the bacteria, but it also appears that the bacteria residing within a biofilm are them- selves less susceptible to antibiotics (Hoyle et al 1992; Suci et al 1994). Once bacteria are part of a biofilm they become distinctly different from their planktonic counter-parts, visibly and genetically (Donlan and Costerton 2002). This change is co-ordinated by the ability of bacteria to communicate via quorum sensing molecules, which are transported along channels within the biofilm (Bjarnsholt et al 2005). Quorum sensing molecules convey useful information such as population density and nutrient availability, which the bacteria can respond to. For example, the bacteria can reduce their metabolism, or divide less frequently. Many common antibiotics rely on a high metabolic rate or rapid bacterial replication in order to kill bacteria, so become less effective against slow growing biofilm bacteria (Duguid et al 1992). Consequently the bacteria are difficult to destroy using antibiotics, and infections persist.

A further complication is that biofilms are not static. A pioneering species will initially colonise the wound, but will in time be joined by other species. The number of bacterial species, and the abundance of each, will vary, both between individual wounds, and across the lifetime of the biofilm (Gjødsbøl et al 2006). In particular, initial colonisation by aerobic bacteria can make the wound bed hypoxic, or low in oxygen, which creates a suitable environment for many anaerobic species. Far less is known about the role of anaerobic species in impaired wound healing, but they are increasingly being highlighted as major contributors to chronic wounds (Wall et al 2002).

The multi-species nature of biofilms can necessitate the use of a cocktail of antibiotics to target all the species within the chronic wound. However, intensive use of antibiotics over many years is resulting in the emergence of antibiotic resistance, as the rapidity of bacterial reproduction means that evolution via natural selection occurs quickly. Furthermore, some bacteria are able to directly transfer genetic material to one another, 
enabling them to share their antibiotic resistance genes (Hausner and Wuertz 1999). If over time a strain acquires resistance to multiple antibiotics it can become virtually impossible to treat, a prime example being the much-feared MRSA.

Because of the reasons discussed, antibiotics have limited success at completely destroying the bacterial presence in chronic wounds. This means the ever-present biofilm can continuously shed planktonic bacteria into the wound. These bacteria divide rapidly and are often highly invasive, releasing toxins and damaging enzymes into the wound. These aid the survival of the bacteria by helping them to evade or attack the human immune system. Many species can also kill human cells, causing necrosis, which enlarges the wound.

The damage the bacteria cause to the surrounding tissue results in an inflammatory response. As described, the immune response is ineffective at removing the highly resistant biofilm. Consequently a chronic inflammatory state is induced (Herrick et al 1992). The recruited immune cells release pro-inflammatory signals, which in turn recruit more immune cells to sustain the inflammation. They also release enzymes which degrade the surrounding tissue, causing more damage. A strong, long-lasting inflammatory response prevents cell growth, which is necessary to replace the dead and damaged cells (Rayment and Upton 2009). In people who already suffer from a reduced ability to heal a sustained inflammatory response can be catastrophic, and lead to wounds that can take years to heal.

For the time being the normal practice for treating infected chronic wounds is antimicrobial dressings and 'debridement', the physical removal of infected or dead tissue and as much of the biofilm as possible. In extreme cases amputation of the affected region may be required to prevent a lethal systemic infection, but recurrence of a chronic wound is a common complication. Research into chronic wounds is increasing our understanding of the phenomena, but slowly revealing an intricate and complex system. New methods and treatments are being developed to address this problem, aided by the improvements in our understanding. However, there is still a long way to go before we can eradicate this affliction completely.

\section{References}

American Diabetes Association 1999 Consensus Development Conference on Diabetic Foot Wound Care: 7-8 April 1999, Boston, Massachusetts. Diabetes Care, 22 (8): 1354-60.

Bjarnsholt, T, Jensen, P $\emptyset$, Burmølle, $M$, Hentzer, M, Haagensen, J A J, Hougen, H P, Calum, H, Madsen, K G, Moser C, Molin, S, Høiby, N and Givskov, M 2005 Pseudomonas aeruginosa Tolerance to Tobramycin, Hydrogen Peroxide and Polymorphonuclear Lukocytes Is Quorumsensing Dependent. Microbiology, 151 (2): 373-83. http://dx.doi.org/10.1099/ mic.0.27463-0

Costerton, J W 2007 The Biofilm Primer. Berlin: Springer.

Davis, S C, Ricotti, C, Cazzaniga, A, Welsh, E, Eaglstein, W H, and Mertz, P M 2008 Microscopic and Physiologic Evidence for Biofilm-associated Wound Colonization in Vivo. Wound Repair and Regeneration, 16 (1): 23-9. http://dx.doi.org/10.1111/ j.1524-475X.2007.00303.X

Donlan, R M and Costerton, J W 2002 Biofilms: Survival Mechanisms of Clinically Relevant Microorganisms. Clinical Microbiology Reviews, 15 (2): 167-93. http:// dx.doi.org/10.1128/CMR.15.2.167193.2002

Drenkard, E 2003 Antimicrobial Resistance of Pseudomonas Aeruginosa Biofilms. Microbes and Infection, 5(13): 1213-9. http:// dx.doi.org/10.1016/j.micinf.2003.08.009

Duguid, I G, Evans, E, Brown, M R and Gilbert, P 1992 Growth-rate-independent Killing by Ciprofloxacin of Biofilm-derived Staphylococcus Epidermidis; Evidence for Cell-cycle Dependency. Journal of Antimi- 
crobial Chemotherapy, 30 (6): 791-802. http://dx.doi.org/10.1093/jac/30.6.791

Falanga, V 1993 Chronic Wounds: Pathophysiologic and Experimental Considerations. Journal of Investigative Dermatology, 100 (5): 721-5. http://dx.doi. org/10.1111/1523-1747.ep12472373

Gjødsbøl, K, Christensen, J J, Karlsmark, T, Jørgensen, B, Klein, B $\mathbf{M}$ and Krogfelt, K A 2006 Multiple Bacterial Species Reside in Chronic Wounds: A Longitudinal Study. International Wound Journal, 3 (3): 225-31. http://dx.doi.org/10.1111/ j.1742-481X.2006.00159.x

Green, J and Jester, R 2009 Health-related Quality of Life and Chronic Venous Leg Ulceration: Part 1. British Journal of Community Nursing, 14 (12): S12-S17.

Gurjala, AN, Geringer, M R, Seth, A K, Hong, S J, Smeltzer, M S, Galiano, R D, Leung, K P and Mustoe, T A 2011 Development of a Novel, Highly Quantitative in Vivo Model for the Study of Biofilm-impaired Cutaneous Wound Healing. Wound Repair and Regeneration, 19 (3): 400-10. http://dx.doi. org/10.1111/j.1524-475X.2011.00690.x

Hausner, M and Wuertz, S 1999 High Rates of Conjugation in Bacterial Biofilms as Determined by Quantitative in Situ Analysis. Applied and Environmental Microbiology, 65 (8): 3710-3.

Herrick, S E, Sloan, P, McGurk, M, Freak, L, McCollum, C N and Ferguson, M W 1992 Sequential Changes in Histologic Pattern and Extracellular Matrix Deposition during the Healing of Chronic Venous Ulcers. The American Journal of Pathology, 141 (5): 1085-95.

Hoyle, B D, Wong, C K and Costerton, J W 1992 Disparate Efficacy of Tobramycin on $\mathrm{Ca}^{2+}, \mathrm{Mg}^{2+}$, and HEPES-treated Pseudomonas Aeruginosa Biofilms. Canadian Journal of Microbiology, 38 (11): 1214-8. http://dx.doi.org/10.1139/m92-201
James, G A, Swogger, E, Wolcott, R, deLancey Pulcini, E, Secor, P, Sestrich, J, Costerton, J W and Stewart, P S 2008 Biofilms in Chronic Wounds. Wound Repair and Regeneration, 16 (1): 37-44. http://dx.doi.org/10.1111/j.1524475X.2007.00321.x

Mustoe, T A, O'Shaughnessy, $\mathbf{K}$ and Kloeters, 02006 Chronic Wound Pathogenesis and Current Treatment Strategies: A Unifying Hypothesis. Plastic and Reconstructive Surgery 117 (7): 35S-41S. http://dx.doi.org/10.1097/01. prs.0000225431.63010.1b

Posnett, J and Franks, P J 2008 The Burden of Chronic Wounds in the UK. Nursing Times, 104 (3): 44-5.

Rayment, E A and Upton, Z 2009 Finding the Culprit: A Review of the Influences of Proteases on the Chronic Wound Environment. International Journal of Lower Extremity Wounds, 8 (1): 19-27. http:// dx.doi.org/10.1177/1534734609331596

Schierle, C F, De la Garza, M, Mustoe, T A and Galiano, R D 2009 Staphylococcal Biofilms Impair Wound Healing by Delaying Reepithelialization in a Murine Cutaneous Wound Model. Wound Repair and Regeneration, 17 (3): 354-9. http://dx.doi.org/10.1111/j.1524475X.2009.00489.X

Suci, P A, Mittelman, M W, Yu, F P and Geesey, G G 1994 Investigation of Ciprofloxacin Penetration into Pseudomonas Aeruginosa Biofilms. Antimicrobial Agents and Chemotherapy, 38 (9): 2125-33. http:// dx.doi.org/10.1128/AAC.38.9.2125

Wall, I B, Davies, C E, Hill, K E, Wilson, M J, Stephens, P, Harding, K G and Thomas, D W 2002 Potential Role of Anaerobic Cocci in Impaired Human Wound Healing. Wound Repair and Regeneration, 10 (6): 346-53. http://dx.doi.org/10.1046/ j.1524-475X.2002.t01-1-10602.x 
How to cite this article: Davis, N 2013 Chronic Wounds: The Persistent Infection Problem. Opticon1826, (15): 9, pp.1-5, DOl: http://dx.doi.org/10.5334/opt.bg

Published: 12 August 2013

Copyright: ( 2013 The Author(s). This is an open-access article distributed under the terms of the Creative Commons Attribution 3.0 Unported License (CC-BY 3.0), which permits unrestricted use, distribution, and reproduction in any medium, provided the original author and source are credited. See http://creativecommons.org/licenses/by/3.0/. ] $\mathbf{u}\left[\begin{array}{l}\text { Opticon1826 is a peer-reviewed open access journal published by } \\ \text { Ubiquity Press }\end{array}\right.$ 